\title{
Characterization of photoelectrochemical cells for water splitting by electrochemical impedance spectroscopy
}

\author{
Tânia Lopes, Luísa Andrade, Helena Aguilar Ribeiro, Adélio Mendes* \\ Laboratório de Engenharia de Processos, Ambiente e Energia (LEPAE), Faculdade de Engenharia da Universidade do Porto, Rua Roberto Frias, \\ 4200-465 Porto, Portugal
}

\section{A R T I C L E I N F O}

Article history:

Received 12 December 2009

Received in revised form

17 March 2010

Accepted 1 April 2010

Available online 5 May 2010

\section{Keywords:}

Hydrogen

Water splitting

PEC cells

Electrochemical impedance spectros-

copy

Electrical analogs

\begin{abstract}
A B S T R A C T
The photocurrent-voltage characteristic of a photoelectrochemical cell for solar hydrogen production via water splitting, using undoped-hematite as photoanode, was obtained. Photoelectrochemical characteristics of the cell were also investigated by electrochemical impedance spectroscopy. Both techniques were carried out in the dark and under illumination. The analysis of the frequency spectra for the real and imaginary parts of the complex impedance allowed obtaining equivalent electrical analogs for the PEC cell operating in the dark and under 1 sun simulated illumination. Additionally, different electrode configurations were used (two and three-electrode arrangements). The twoelectrode configuration allowed the study of the overall charge transfer phenomena occurring at the semiconductor, within the electrolyte and at the counter-electrode side of the cell, whereas the three-electrode configuration gave more detailed information concerning the double charged layer at the semiconductor/electrolyte interface.
\end{abstract}

(c) 2010 Professor T. Nejat Veziroglu. Published by Elsevier Ltd. All rights reserved.

\section{Introduction}

The increasing public awareness concerning carbon dioxide emissions and the enhanced depletion of fossil fuel reserves motivates the development of technology based on alternative energy sources [1]. With $120 \mathrm{PW}$ of solar energy striking the surface of the earth at any given moment, the challenge in converting sunlight into electricity via photovoltaic solar cells is to reduce dramatically the cost per watt of delivered solar electricity. [2,3], Nowadays, harvesting sunlight energy by using photovoltaic technology has been considered an essential pathway to energy sustainability [4]. Nevertheless, due to the variability of daily solar radiation, an effective method to store energy for later dispatch is needed [5]. A practical way to convert sunlight into a storable energy form is using a photoelectrochemical (PEC) cell, enabling the water split into hydrogen and oxygen by light-induced electrochemical processes [6]. Hydrogen production from photoelectrochemical water splitting represents a prospective alternative of combining photovoltaic cells with an electrolysis system $[7,8]$. The major advantage is that energy capture, conversion and storage are combined in a single integrated system [3].

Hydrogen has the potential to be a sustainable carbonneutral fuel since it can be produced from a renewable source and converted into electricity at relatively high efficiencies; it uses water as raw material and can be stored either in gaseous, liquid or metal hydride form. Moreover, it can be transported over large distances and is environmentally compatible since its production, storage, transportation and end use do not produce pollutants and greenhouse-effect gases $[6,9]$.

The direct photoelectrolysis of water was first achieved with a $\mathrm{TiO}_{2}$ semiconductor photoelectrode in a pioneer work reported by Fujishima and Honda, in the 70s. [10-12]

\footnotetext{
* Corresponding author. Tel.: +351 225081695; fax: +351 225081449.

E-mail address: mendes@fe.up.pt (A. Mendes).
}

0360-3199/\$ - see front matter ( 2010 Professor T. Nejat Veziroglu. Published by Elsevier Ltd. All rights reserved.

doi:10.1016/j.ijhydene.2010.04.001 
However, this semiconductor requires a photonic energy of at least $3.2 \mathrm{eV}$ and so only a small fraction of solar spectrum can be used. During the 70s and 80s significant improvements were made to find new oxide semiconductors with small and well positioned band gaps, proper to harvest visible light and capable of conducting alone water splitting under solar radiation with attractive efficiencies [2]. As an example, doped hematite nanostructures, such as nanowires and nanorods, are presently envisaged as very promising water splitting photoanodes $[11,12]$. However, state-of-the-art photocurrent densities for PEC cells still remain in the range $2-3 \mathrm{~mA} \mathrm{~cm}^{-2}$ at $1.23 \mathrm{~V}_{\mathrm{RHE}}$. The low quantum efficiency observed for these photoanodes is mainly related with the low mobility of charge carriers due to charge transfer hopping mechanisms [13]. In order to improve the energy efficiency of such devices, several efforts in shifting the activity of the photoanode into the visible have been developed in the past few years [14].

The principle of converting sunlight into hydrogen by water photoelectrolysis is illustrated in Fig. 1. The photoelectrochemical water-splitting cell consists of a photoelectrode (semiconductor) that absorbs photons with sufficient energy to inject electrons from the valence to the conduction band of the semiconductor, creating electron-hole pairs. Holes oxidize water in the semiconductor surface, while electrons percolate through the semiconductor layer and reach the counter-electrode, via the external circuit, to promote water reduction at its surface $[2,15]$. The cycle is then closed when the electrolyte anions generated at the counterelectrode diffuse back to the surface of the semiconductor to recombine with holes. The corresponding oxidation and reduction reactions are written hereafter:

$4 \mathrm{OH}^{-}+4 \mathrm{~h}^{+} \rightarrow \mathrm{O}_{2}+2 \mathrm{H}_{2} \mathrm{O}$

$E_{\mathrm{O}_{2} / \mathrm{OH}^{-}}^{\circ}=0.401 \mathrm{~V}_{\mathrm{RHE}}$

$4 \mathrm{H}_{2} \mathrm{O}+4 \mathrm{e}^{-} \rightarrow 2 \mathrm{H}_{2}+4 \mathrm{OH}^{-}$

$E_{\mathrm{H}_{2} \mathrm{O} / \mathrm{H}_{2}}^{\circ}=-0.828 \mathrm{~V}_{\mathrm{RHE}}$

Since Fujishima and Honda used a $\mathrm{TiO}_{2}$ photoelectrode with a large band gap able to use only $5 \%$ of the solar

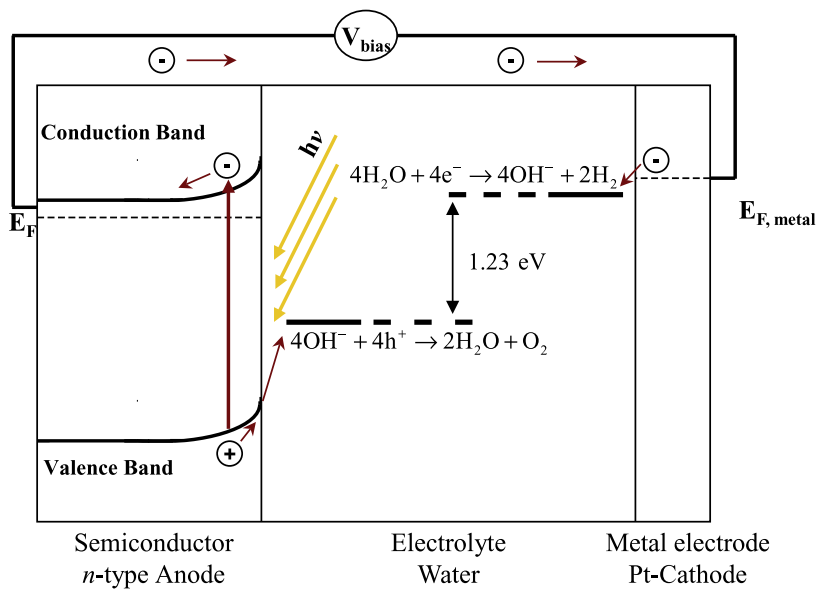

Fig. 1 - Schematic representation of the relevant processes involved in the photohydrolysis of water. spectrum, their devices showed limited potentialities for efficiently produce solar hydrogen. In fact, most of the semiconductors available for water splitting have a large energy band gap or the band edge potentials are not suitable for oxygen and hydrogen evolution. For efficient water cleavage, the conduction band of the n-type semiconductor needs to be positioned at a more negative potential than the reduction potential of water (i.e. $E_{\mathrm{c}}>\mathrm{E}_{\text {red }}\left(\mathrm{H}_{2} / \mathrm{H}^{+}\right)$), while the valence band needs to be more positive than the oxidation reaction (i.e. $\left.E_{\mathrm{v}}<\mathrm{E}_{\mathrm{Ox}}\left(\mathrm{OH}^{-} / \mathrm{O}_{2}\right)\right)$. Despite the intensive research efforts mentioned before, no semiconductor materials have yet been found that fulfill all the requirements needed to generate solar hydrogen by water splitting. Hematite semiconductor, compared with other materials, shows some of the so desired properties. In theory, its indirect band gap of approximately $2.2 \mathrm{eV}$ allows the utilization of almost $40 \%$ of the incident solar spectrum. Moreover, its abundance together with low cost, chemical stability and low toxicity allows its industrial utilization. [2,16] As a drawn back, hematite semiconductor has a conduction band edge positioned at an energy level inferior of the reversible hydrogen potential [2]. Consequently, photoelectrolytic hematite-based devices promote water photoreduction with the help of an external energy source, such as a photovoltaic cell. For that an arrangement known as tandem cell is used [2].

The present work reports the study of photoelectrochemical cells based on metal oxide semiconductor of undoped-hematite by current-voltage characteristics curves and also by using electrochemical impedance spectroscopy (EIS) in the dark and under illumination. The use of EIS analysis targeted to characterize the major internal charge transfer resistances that limit the performance of the cells under study with undoped$\mathrm{Fe}_{2} \mathrm{O}_{3}$ as photoanode $[13,17]$. Even though EIS is relatively easy to apply, the interpretation of the results is often complex and requires the use of suitable theoretical models. The use of equivalent electrical analogs to fit EIS data is therefore envisaged as an important tool to identify and interpret the charge transfer phenomena occurring in the PEC cell under typical operating conditions [18]. This approach ultimately allows determining electrochemical parameters that help developing the best strategy to obtain photoelectrodes with optimal characteristics. However, there are mostly no reported studies using 2-electrode EIS analysis to characterize a PEC cell with a hematite photoanode. In spite of the fact that undopedhematite is an insulator and so considerable photocurrents cannot be obtained, the use of this photoanode allows to identify the main electron transport limitations occurring in this simple system. Undoped hematite was taken here as a case study.

\section{Experimental}

\subsection{Photoelectrochemical cell setup}

In the present work, a configuration of a PEC cell known as "cappuccino" was chosen to perform the electrochemical characterization [19]. The cappuccino cell, shown in Fig. 2, is made of polyetheretherketone (Erta Peek ${ }^{\circledR}$ ) and has a $20 \mathrm{~mm}$ diameter uncoated fused silica window (Robson Scientific, 

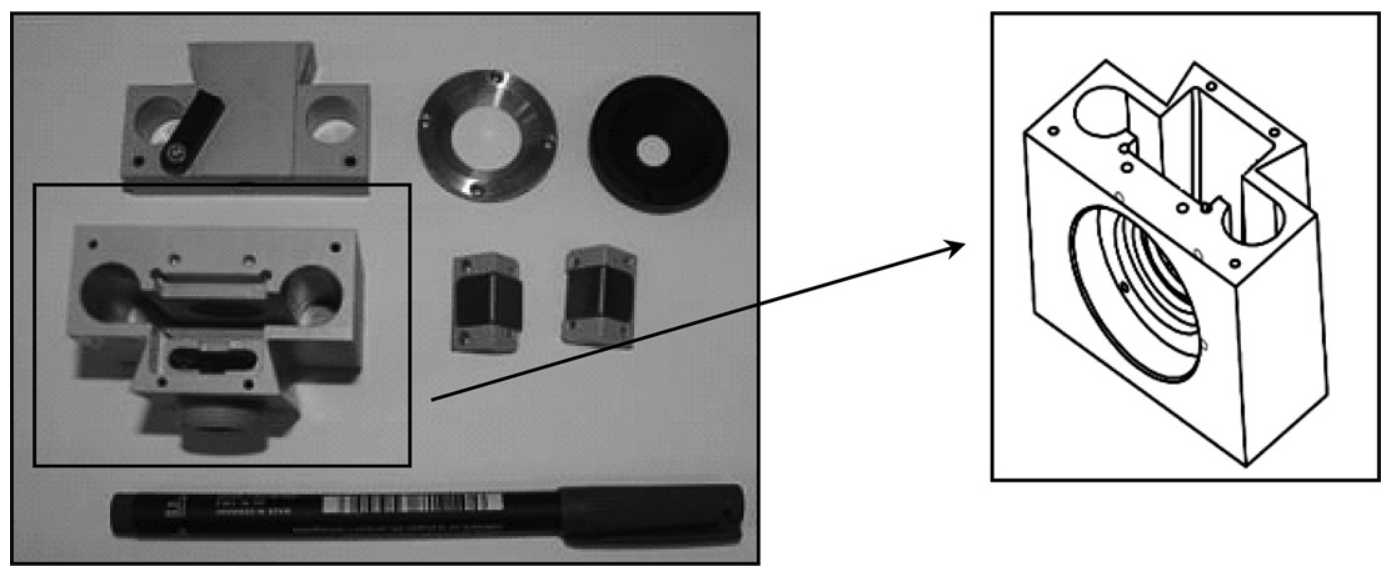

Fig. 2 - Detail of the "cappuccino" PEC cell.

England) pressed against an o-ring by a metallic window part. The cell was filled with an electrolyte solution consisting of 1.0 $\mathrm{M} \mathrm{NaOH}\left(25^{\circ} \mathrm{C}, \mathrm{pH}=13.3\right)[11,17]$ in which the photoanode was immersed. The latter comprised a $2 \mathrm{~mm}$-thick conducting glass (FTO glass, 7-15 W/square) coated with undopedhematite (prepared by ENI-Novara by spray pyrolysis as described elsewhere [20-22]). The total immersed active surface area was approximately $2.5 \mathrm{~cm}^{2}, 0.5 \mathrm{~cm}^{2}$ of which being illuminated through an external mask. A 99.9\% pure platinum wire (Alfa Aeasar ${ }^{\circledR}$, Germany) was used as counterelectrode.

The electrochemical impedance spectroscopy measurements were performed using two configurations. In a standard three-electrode configuration the $\mathrm{Ag} / \mathrm{AgCl} / \mathrm{Sat} \mathrm{KCl}$ electrode (Metrohm, Switzerland) was used as reference electrode; the platinum wire as counter-electrode and the photoanode as working electrode. In a two-electrode configuration, the reference electrode of the electrochemical workstation was short-circuited with the counter-electrode of the PEC.

\subsection{I-V measurements}

The photocurrent-voltage (I-V) characteristic curve was obtained by applying an external potential bias to the cell and measuring the generated photocurrent using a ZENNIUM workstation (Zahner Elektrik, GmbH). The measurements were performed in the dark and under simulated sunlight, AM $1.5 \mathrm{G}\left(150 \mathrm{~W}\right.$ Xe lamp, $1000 \mathrm{~W} \mathrm{~m}^{-2}, 25^{\circ} \mathrm{C}$ ) calibrated with a c-Si photodiode, at a scan rate of $50 \mathrm{mV} \mathrm{s}^{-1}$ between 0.7 and 1.8 $\mathrm{V}_{\mathrm{RHE}}$. A standard three-electrode configuration was used.

\subsection{EIS measurements}

Electrochemical impedance spectroscopy is a dynamic technique where a small potential sinusoidal perturbation is applied to the system and the amplitude and phase shift of the resulting current response are measured. A ZENNIUM workstation (Zahner Elektrik, $\mathrm{GmbH}$ ) was used to perform EIS measurements in either a three or two-electrode configuration. The frequency range was $1 \mathrm{~Hz}-100 \mathrm{kHz}$ and the magnitude of the modulation signal was $10 \mathrm{mV}$. All the measurements were performed at room temperature and at $0.4 \mathrm{~V}$ [17]. The EIS spectra were fitted to an appropriate electrical analog by means of the ZView ${ }^{\circledR}$ software (Scribner Associates Inc.).

\section{Results and discussion}

\subsection{Photocurrent-voltage characteristics}

Fig. 3 shows the I-V curves for undoped- $-\mathrm{Fe}_{2} \mathrm{O}_{3}$ in the dark and under simulated sunlight ( $\mathrm{AM} 1.5 \mathrm{G}, 1000 \mathrm{~W} \mathrm{~m}^{-2}$ ). In the measured under dark conditions it is noticed that the current rises steeply to voltages higher than 1.6 when the called dark current set in.

Analyzing the I-V curve under dark conditions it is noticed that, for potentials higher than $1.6 \mathrm{~V}_{\mathrm{RHE}}$, the electrocatalytic oxygen evolution starts - known as dark current. For this reason, under illumination the current is negligible to

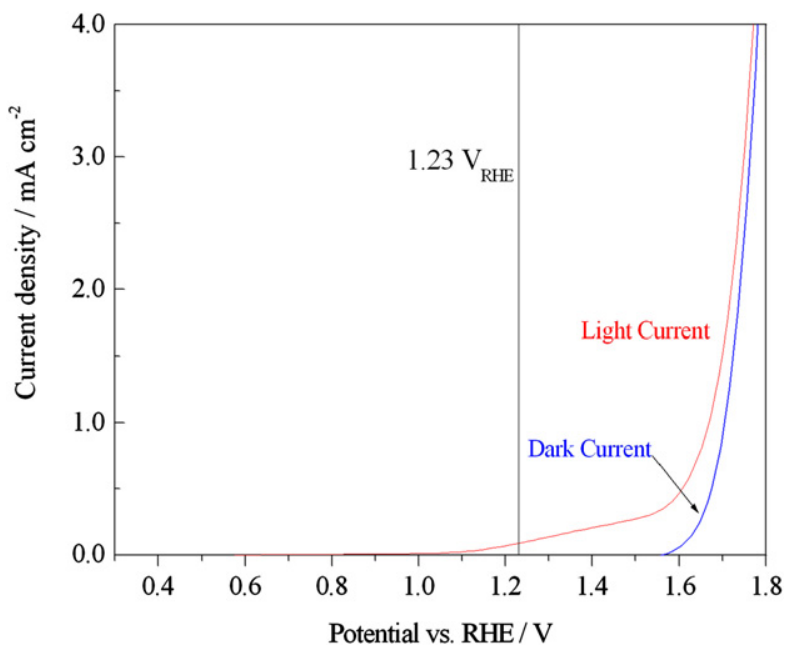

Fig. 3 - Photocurrent-voltage curves of the undoped-Fe $\mathrm{O}_{3}$ electrode in the dark and under 1 sun simulated light (AM 1.5G). 
potentials higher than $1.6 \mathrm{~V}_{\mathrm{RHE}}$ [11]. At the potential of the reversible oxygen electrode (1.23 $\mathrm{V}_{\mathrm{RHE}}$ ), the photocurrent density is $89.7 \mu \mathrm{A} \mathrm{cm}^{-2}$. This is in agreement of literature results: undoped- $\mathrm{Fe}_{2} \mathrm{O}_{3}$ acts as an insulator when used as a photoelectrode in a PEC cell, with typical values in the order of tens of $\mu \mathrm{A} \mathrm{cm}^{-2}$ [11]. In fact, these low photocurrents are mainly ascribed to poor transport properties, which lead to low conductivities and limited photoresponse. Moreover, it is often reported short charge carrier diffusion lengths and slow kinetics of water oxidation by the valence band holes at the surface of the semiconductor. Consequently, most of the holes are created in the bulk and will recombine with electrons from the conduction band before reaching the semiconductor/electrolyte interface [16].

\subsection{Electrochemical impedance measurements}

Fig. 4 shows the impedance spectra for the two-electrode configuration. Here the overall processes occurring in the cell, namely, in the semiconductor, in the electrolyte and at the counter-electrode side, are evaluated in the dark and under simulated sunlight conditions. As observed in Fig. 4, the impedance spectrum is strongly affected by the light intensity applied onto the PEC cell. In fact, the internal resistance corresponding to the overall charge transfer process under illumination is significantly lower than in dark conditions. Additionally, the Nyquist diagram obtained in the dark shows an apparent semicircle in the overall frequency range - Fig. 4 (a), meaning that the impedance behavior corresponding to charge transfer resistances in the semiconductor and in the electrolyte solution are overlapped. This is in agreement with the Bode plots shown in Fig. 4(b), where only one constant time is identified $(|Z|$ us. frequency shows a single straight line in the low and middle-frequency range). Not surprisingly, these findings are easily related to the cappuccino cell design. In fact, there is a leading diffusion resistance of the $\mathrm{OH}^{-}$ions in the electrolyte, which is ascribed to the long pathway between the surface of the platinum counter-electrode and the semiconductor/electrolyte interface. Under illumination, the semicircles corresponding to the charge-transfer resistance in the semiconductor and the diffusion within the electrolyte are still indistinguishable. However, Fig. 4(b) clearly shows two time constants denoted by the two peaks in the Bode-Phase diagram. The low- and middle-frequency peaks thus correspond to the diffusion within the electrolyte and the electron transport/recombination process in the semiconductor, respectively.

The charge transfer process at the platinum counter-electrode/electrolyte interface, typically observed in the high frequency range, cannot be noticed in the Bode plot. However, at the inset of Fig. 4(a), a very small semicircle appears in the high frequency range, ascribed to the charge-transfer process in the platinum counter-electrode under illumination. [23,24] This is not observed for dark conditions because the resistances involved are several orders of magnitude above the resistance at that interface.

Electrical analogs, as these presented in Table 1, were used to fit the EIS experimental data. Although these models do not provide a phenomenological interpretation of the charge transfer processes involved, they allowed to identify and
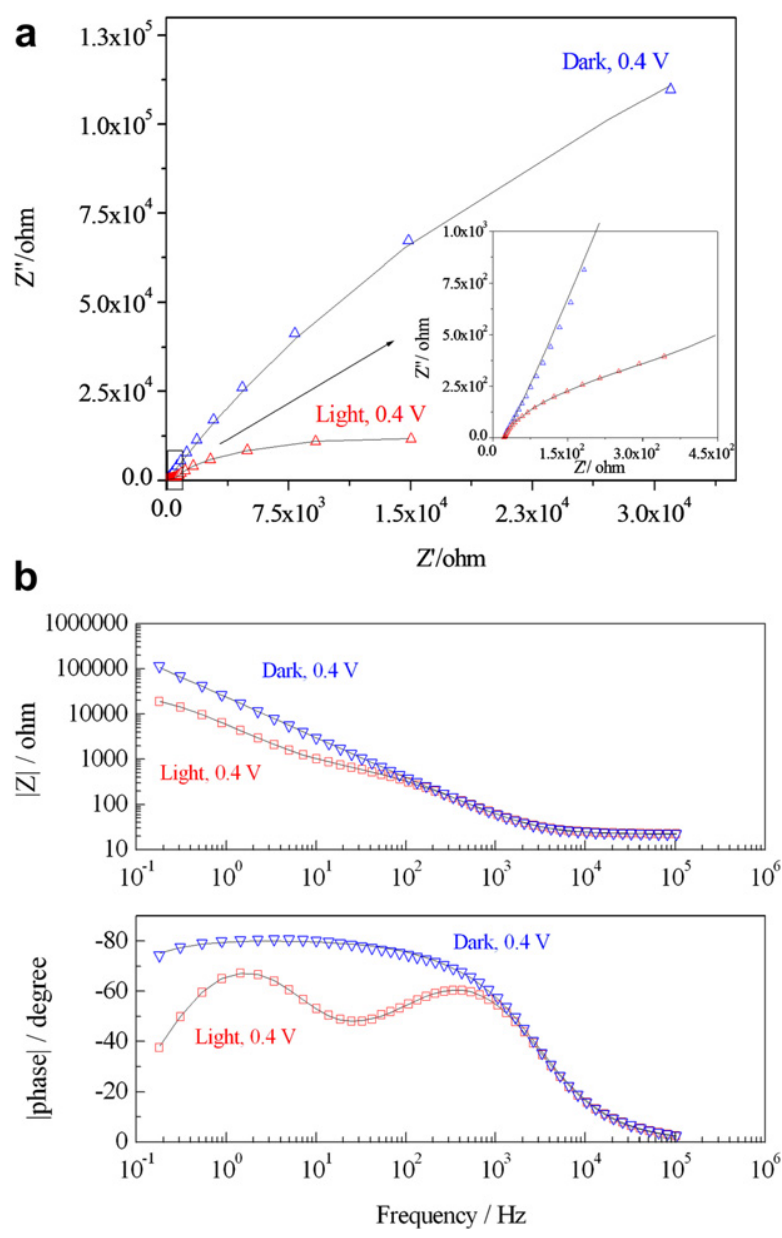

Fig. 4 - a) Nyquist diagram and b) Bode plots obtained in the dark and under simulated sunlight at $0.4 \mathrm{~V}$ in a 2electrode configuration. Symbols represent the experimental data; solid lines represent the fitting based on the equivalent electrical analogs shown in Table 1.

quantify resistive and capacitive elements that are somehow related with the main phenomena occurring at the PEC. This way, the experimental data obtained under 1 sun illumination and in the dark was fitted to different models, as presented hereafter. In both models, $R_{\mathrm{s}}$ is the series resistance, which includes the sheet resistance of the TCO glass and the external contact resistance of the cell (e.g. wire connections). The parallel $R_{\mathrm{SC}}$ and $C_{\mathrm{SC}}$ elements characterize the charge transfer resistance and the double layer capacitance in the semiconductor, respectively. In the same way, the platinized counter-electrode is characterized by a charge-transfer resistance, $R_{\mathrm{CE}}$, and a double layer capacitance, $C_{\mathrm{CE}}$. In the dark, the diffusion of ions $\mathrm{OH}^{-}$within the electrolyte solution is represented by a Warburg element, $\mathrm{W}_{\mathrm{E}}$ [25]. Under simulated sunlight conditions the electrical analog is similar to the one presented for dark conditions, except in the low frequencies range representing the diffusion of ions $\mathrm{OH}^{-}$within the electrolyte. In this case, the mass transport is no longer based on a Nernst diffusion process; therefore it cannot be modeled by a Warburg circuit element. In fact, the Nyquist plot does not present a $45^{\circ}$ diagonal line at low frequencies, a typical 
Table 1 - Equivalent electrical analogs used for modeling the electrochemical cell comprising an undoped-Fe $\mathrm{O}_{3}$

semiconductor in a 2-electrode configuration. The corresponding parameters were obtained for dark (left) and simulated 1 sun illumination (right) conditions at a potential bias of $0.4 \mathrm{~V}$.

Dark
$R_{\mathrm{S}}=22.03 \Omega$
$\mathrm{R}_{\mathrm{SC}}=4.90 \times 10^{4} \Omega$
$\mathrm{CPE} \mathrm{SC}=3.55 \times 10^{-5} \mathrm{~F}$
$n_{\mathrm{SC}}=0.99$
$\mathrm{~W}_{\mathrm{E}}-\mathrm{R}=4.76 \times 10^{6} \Omega$
$\mathrm{R}_{\mathrm{CE}}=10.00 \Omega$
$\mathrm{CPE}_{\mathrm{CE}}=1.47 \times 10^{-4} \mathrm{~F}$
$n_{\mathrm{CE}}=0.84$

Light

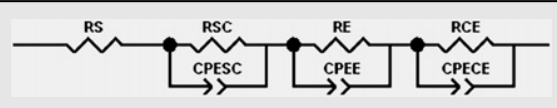

Resistive parameters: $R_{S}, R_{S C}, W_{E}-R, R_{C E}, R_{E}$; Capacitive parameters: $C P E_{S C}, C P E_{C E}, C P E_{E}$.

SC, E and CE stand for semiconductor, electrolyte and counter-electrode, respectively.

feature of diffusion-like charge transfer processes [26]. Under illumination the diffusion of the ionic species, which is now represented by an $\mathrm{R} / / \mathrm{C}$-circuit element shows impedance values lower than those observed under dark conditions.

In addition, under illumination electrons are able to flow to the external circuit due to the photoexcitation of the conduction band electrons. On the other hand, in the dark there is only an equilibrium of charges and consequent electron accumulation in the electrodes, responsible for the higher charge transfer resistances. Moreover, the experimental data now tends to define a semicircle, represented by an $R / / C$-circuit, $R_{E} / / C_{E}$. In fact, a quite good agreement between experimental and fitted data was obtained - Fig. 4.

It is important to hold back that, for good fitting purposes, all the chemical capacitances were replaced by constant phase elements (CPE), non-ideal capacitances associated with a non-uniform distribution of current in the heterogeneous materials that constitute the semiconductor and the catalyst. The impedance of a CPE is defined as:

$Z_{\mathrm{CPE}}=\frac{1}{j \omega C^{n}}$

where $n(0<n<1)$ is an empirical constant with no real physical meaning [26]. For ideal capacitors $n=1$.

As previously mentioned, a two-electrode configuration difficult the estimation of the semiconductor and electrolyte impedances due to the observed overlap between the impedance data of these two components of the PEC cell. To overcome this issue and extract more information concerning the charge transfer kinetics at the semiconductor/ electrolyte interface, a three-electrode configuration was therefore considered. In fact, using a $\mathrm{Ag} / \mathrm{AgCl} /$ sat $\mathrm{KCl}$ reference electrode, a counter-electrode and a photoanode with such configuration, allows to isolate the impedance of the double space-charge layer in the semiconductor/electrolyte interface [27]. When a semiconductor is brought into contact with an electrolyte solution in the dark, a space charge layer arises in a region of the semiconductor adjacent to the interface with the electrolyte. Equilibrium of the electrochemical potentials of the two phases is established by electron transfer from the semiconductor to the electrolyte. Consequently, a positive space charge layer appears in the semiconductor side, across which a potential gradient exists. This layer is also denoted as depletion layer since the region is depleted of majority charge carriers. Additionally, a charged layer appears on the electrolyte interface side, consisting of charged ions adsorbed on the solid electrode surface - Helmholtz layer $[28,29]$. Under illumination, photons with energy higher than the semiconductor band gap are absorbed, originating electron-hole pairs or excitons. However, part of these photons may be absorbed in the depletion layer, where the separation of the electron-hole pairs occurs by means of the influence of electric fields. As a consequence, the semiconductor Fermilevel shifts toward its flat-band potential and the Fermi level returns toward its original position before the semiconductor-electrolyte junction was established [29].

The three-electrode configuration allows a more detailed analysis of the semiconductor/electrolyte interface, thus complementing the information obtained with the two-electrode configuration. Fig. 5 shows the impedance spectra obtained for the same PEC cell but in a three-electrode configuration. Here, the processes occurring in the semiconductor/electrolyte interface, composed by the depletion and the Helmholtz layers, are evaluated in the dark and under simulated sunlight conditions. Similar to the results observed with a two-electrode configuration, quite different impedance spectra were obtained in the dark and under illumination. In fact, in dark conditions there is an overlap of the semicircles corresponding to the depletion and the Helmholtz layers, as illustrated in Fig. 5(a) a huge single resistance under the overall frequency range can be observed. Again, this is a consequence of the cell design, which implies the use of a large amount of electrolyte. Furthermore, in the inset of Fig. 5(a), corresponding to the Nyquist diagram under 1 sun simulated conditions, two semicircles can be distinguished: a small semicircle in the high frequency range, ascribed to the charge-transfer process in the semiconductor depletion layer; and the low-frequencies arc, attributed to the electron 


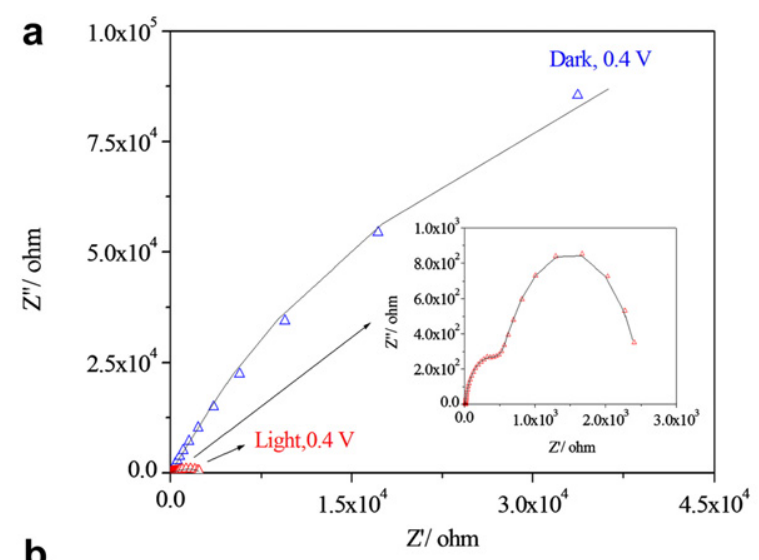

b
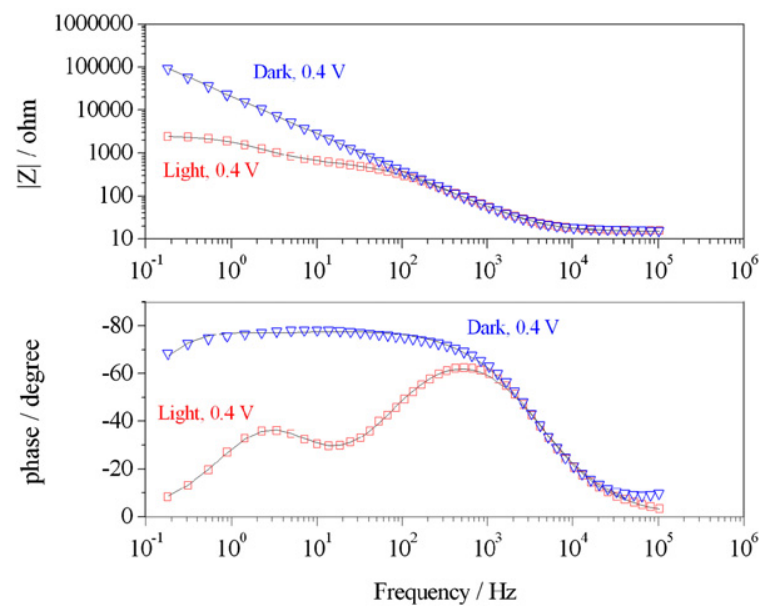

Fig. 5 - a) Nyquist diagram and b) Bode plots obtained in the dark and under simulated sunlight at $0.4 \mathrm{~V}_{\mathrm{Ag} / \mathrm{AgCl}}$ in a three-electrode configuration. Symbols represent the experimental data; solid lines represent the fitting based on the equivalent electrical analogs shown in Table 2. transfer at the Helmholtz layer. [13,17,25,27] The same conclusions can be drawn from the Bode plots - Fig. 5(b): the right-hand side peak in the Bode-phase diagram corresponds to the depletion layer, whereas the left-hand side peak arises from the impedance at the Helmholtz layer. It is worth noting that in this case, only the electrolyte layer adjacent to the solid/liquid interface is analyzed, which corresponds to much lower impedance compared to that of the bulk. This explains the reduced amplitude of the corresponding peak in the Bodephase diagram - Fig. 4(b).

The electrical analog presented in Table 2 was used to fit the EIS data obtained with the three-electrode configuration in the dark and under illumination. Here, the R//CPE-circuit, $R_{D p} / /$ $C P E_{\mathrm{Dp}}$ describes the semiconductor depletion layer resistance and the chemical capacitance, respectively. On the other hand, the charge transfer resistance in the Helmholtz layer is represented by $R_{H}$, while the $C P E_{H}$ and $W_{H}$ elements correspond to the recharged Helmholtz layer and Warburg diffusion impedance, respectively. Finally, $R_{S}$ is the series resistance of the cell.

As expected, the charge transfer resistance in the depletion layer of the semiconductor is higher when the cell operates in dark conditions $\left(R_{\mathrm{Dp}}=3.41 \times 10^{5} \Omega\right)$. Moreover, under illumination, the electron Fermi level in the semiconductor approaches its flat-band potential, resulting in a small depletion layer thickness and, consequently, in a higher chemical capacitance $\left(\mathrm{CPE}_{\mathrm{Dp}}^{\mathrm{Light}}>C P E_{\mathrm{Dp}}^{\mathrm{Dark}}\right)$ [28]. Comparing the chemical capacitances in the dark $\left(C P E_{D p}<C P E_{H}\right)$, it can be concluded that the depletion layer thickness is significantly higher than the Helmholtz layer, explained by the smaller carrier densities in the semiconductor [29]. In what concerns the Helmholtz layer behavior, the potential across it is almost independent of the external applied potential and the illumination conditions [29]. Therefore, the correspondent charge-transfer resistance and capacitance should be similar in the dark and under illumination. In fact, the $R_{H}$ and $C P E_{H}$ values presented in Table 2 do not change significantly upon illumination. Opposing evidence was found for the Warburg element, which suggests a higher contribution of the ionic species diffusion for the overall impedance of the system under dark conditions.

Table 2 - Equivalent electrical analogs used for modeling the electrochemical cell comprising an undoped-Fe $\mathrm{O}_{3}$ semiconductor in a 3-electrode configuration. The corresponding parameters were obtained for dark (left) and simulated 1 sun illumination (right) conditions at a potential bias of $0.4 \mathrm{~V}_{\mathrm{Ag} / \mathrm{AgCl}}$.

Dark

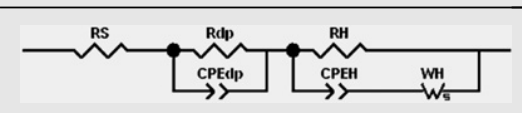

$R_{\mathrm{s}}=15.00 \Omega$

$R_{\mathrm{Dp}}=3.41 \times 10^{5} \Omega$

$\mathrm{CPE}_{\mathrm{Dp}}=8.90 \times 10^{-6} \mathrm{~F}$

$n_{\mathrm{Dp}}=0.94$

$R_{\mathrm{H}}=2.03 \times 10^{3} \Omega$

$\mathrm{CPE}_{\mathrm{H}}=8.80 \times 10^{-5} \mathrm{~F}$

$n_{\mathrm{H}}=0.82$

$\mathrm{W}_{\mathrm{H}}-\mathrm{R}=5.33 \times 10^{3} \Omega$
Light

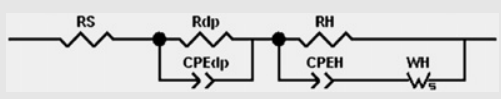

$R_{S}=15.46 \Omega$

$R_{\mathrm{Dp}}=5.04 \times 10^{2} \Omega$

$\mathrm{CPE}_{\mathrm{Dp}}=1.00 \times 10^{-5} \mathrm{~F}$

$n_{\mathrm{Dp}}=0.88$

$R_{\mathrm{H}}=2.03 \times 10^{3} \Omega$

$\mathrm{CPE}_{\mathrm{H}}=9.05 \times 10^{-5} \mathrm{~F}$

$n_{\mathrm{H}}=0.89$

$\mathrm{W}_{\mathrm{H}}-\mathrm{R}=3.93 \Omega$

Resistive parameters: $R_{\mathrm{s}}, R_{\mathrm{Dp}}, \mathrm{W}_{\mathrm{H}}-\mathrm{R}, \mathrm{R}_{\mathrm{H}}$; Capacitive parameters: $C P E_{\mathrm{Dp}}, C P E_{\mathrm{H}}$.

$\mathrm{Dp}$, and $\mathrm{H}$ stand for depletion and Helmholtz layers, respectively. 
For the two configurations under study (two and threeelectrodes), the good agreement between the measured and the fitted EIS data shows that the proposed equivalent circuit analogs accurately describe the main charge transfer processes occurring in photoelectrochemical cells consisting of undoped-hematite semiconductors operating at these particular conditions. Analyzing Table 2, the high values observed for the charge transfer resistances in the semiconductor depletion layer, compared with those reported in the literature for doped hematite, confirm the poor performance of the undoped-hematite as a semiconductor for water cleavage [25]. This is mainly ascribed to electron transport limitations and deficient surface charge transfer kinetics.

\section{Conclusions}

A study of photoelectrochemical and electrical properties of undoped- $\mathrm{Fe}_{2} \mathrm{O}_{3}$ was reported. This photoanode showed significantly electron transport limitations, producing a low photocurrent density of about $89.7 \mu \mathrm{A} \mathrm{cm} \mathrm{cm}^{-2}$ at an applied voltage of $1.23 \mathrm{~V}_{\mathrm{RHE}}$. Two different configurations were used to characterize the performance of the photoelectrochemical cell. In both situations, the impedance analysis showed that the charge transfer resistances are significantly reduced under irradiation. With a two-electrode configuration it is difficult to estimate the semiconductor and the electrolyte impedances, due to the overlap between these two components of the PEC cell. Moreover, the phenomena occurring in the electrolyte under illumination and in the dark are different and need to be represented by different electrical analogs. On the other hand, a three-electrode configuration allowed the separation of the overall processes occurring in the semiconductor/electrolyte interface by evaluating the charge transfer phenomena in the depletion and Helmholtz layers. Finally, the results obtained with both configurations can still be extended if the electrolyte amount is reduced, since a thinner electrolyte layer will enable the identification of the impedance behavior ascribed to other components of the cell.

\section{Acknowledgement}

T. Lopes thanks the European Comission for funding (Project NanoPEC - Nanostructured Photoelectrodes for Energy Conversion; contract number 227179) and Dr. Laura Meda (ENI Donegani Institute) for providing the photoanodes. L. Andrade is grateful to the Portuguese Foundation for Science and Techonology (FCT) for her Ph.D grant (reference: SFRH/BD/30464/2006).

\section{REFERENCES}

[1] Grätzel M. Solar energy conversion by dye-sensitized photovoltaic cells. Inorganic Chemistry 2005;44(20):6841-51.

[2] Krol Rvd, Liang Y, Schoonman J. Solar hydrogen production with nanostructured metal oxides. Journal of Materials Chemistry 2008;18(20):2311-20.
[3] Nathan SL. Basic research needs for solar energy utilization. In: Nault Renée M, editor. Report on the basic energy sciences workshop on solar energy utilization. C.I.o. Technology; 2005.

[4] Samuel S, Mao XC. Selected nanotechnologies for renewable energy applications. International Journal of Energy Research 2007;31(6-7):619-36.

[5] Trieb F. Concentrating solar power for the Mediterranean Region, in final report. German Aerospace Center (DLR); 2005.

[6] Grimes, C.A., Varghese O.K., Ranjan S., 2008. Photoelectrolysis, in light, Water, Hydrogen. 115-190.

[7] Bard AJ, Fox MA. Artificial photosynthesis: solar splitting of water to hydrogen and oxygen. Accounts of Chemical Research 1995;28(3):141-5.

[8] Khaselev O, Turner JA. A monolithic photovoltaicphotoelectrochemical device for hydrogen production via water splitting. Science 1998;280(5362):425-7.

[9] Zerta M, Schmidt PR, Stiller C, Landinger H. Alternative World Energy Outlook (AWEO) and the role of hydrogen in a changing energy landscape. International Journal of Hydrogen Energy 2008;33(12):3021-5.

[10] Fujishima A, Honda K. Electrochemical photolysis of water at a semiconductor electrode. Nature 1972;238(5358):37-8.

[11] Kay A, Cesar I, Gratzel M. New benchmark for water photooxidation by nanostructured $\alpha$-Fe2O3 films. Journal of American Chemical Society 2006;128(49):15714-21.

[12] Park JH, Kim S, Bard AJ. Novel carbon-doped TiO2 nanotube arrays with high aspect ratios for efficient solar water splitting. Nano Letters 2006;6(1):24-8.

[13] Aroutiounian VM, Arakelyan VM, Shahnazaryan GE, Stepanyan GM, Turner JA, Kocha SS. Investigations of the Fe1.99Ti0.0103-electrolyte interface. Electrochimica Acta 2000;45(12):1999-2005.

[14] Peharz G, Dimroth F, Wittstadt U. Solar hydrogen production by water splitting with a conversion efficiency of $18 \%$. International Journal of Hydrogen Energy 2007;32(15): 3248-52.

[15] Archer MD, Nozik AJ. In: Nanostructured and photoelectrochemical systems for solar photon conversion. Series on photoconversion of solar energy, vol. 3. London: Imperial College Press; 2008.

[16] Glasscock JA, Barnes PRF, Plumb IC, Savvides N. Enhancement of photoelectrochemical hydrogen production from hematite thin films by the introduction of Ti and $\mathrm{Si}$. The Journal of Physical Chemistry C 2007;111(44):16477-88.

[17] Aroutiounian VM, Arakelyan VM, Shahnazaryan GE, Hovhannisyan HR, Wang H, Turner JA. Photoelectrochemistry of tin-doped iron oxide electrodes. Solar Energy 2007;81(11): 1369-76.

[18] Andrade L, et al. Influence of sodium cations of N3 dye on the photovoltaic performance and stability of dye-sensitized solar cells. ChemPhysChem 2009;10(7):1117-24.

[19] Cesar I, Kay A, Gonzalez Martinez JA, Gratzel M. Translucent thin film Fe2O3 photoanodes for efficient water splitting by sunlight: nanostructure-directing effect of Si-doping. Journal of the American Chemical Society 2006;128(14):4582-3.

[20] Liang Y, Cristina SE, van de Krol R. Photoelectrochemical characterization of sprayed $\alpha$-Fe2O3 thin films: influence of $\mathrm{Si}$ doping and $\mathrm{SnO} 2$ interfacial layer. International Journal of Photoenergy 2008;2008:7.

[21] Duret A, Gratzel M. Visible light-induced water oxidation on mesoscopic $\hat{\mathrm{I}} \pm-\mathrm{Fe} 2 \mathrm{O} 3$ films made by ultrasonic spray pyrolysis. The Journal of Physical Chemistry B 2005;109(36): 17184-91.

[22] Satsangi VR, Kumari S, Singh AP, Shrivastav R, Dass S. Nanostructured hematite for photoelectrochemical generation of hydrogen. International Journal of Hydrogen Energy 2008;33(1):312-8.

[23] Kern R, Sastrawan R, Ferber J, Stangl R, Luther J. Modeling and interpretation of electrical impedance spectra of dye 
solar cells operated under open-circuit conditions. Electrochimica Acta 2002;47(26):4213-25.

[24] O'Hayre R, Cha S-W, Colella W, Prinz FB. Fuel cell fundamentals. New York: John Wiley \& Sons; 2006. XXII, 409.

[25] Boudjemaa A, Boumaza S, Trari M, Bouarab R, Bouguelia A. Physical and photo-electrochemical characterizations of [alpha]-Fe2O3. Application for hydrogen production. International Journal of Hydrogen Energy 2009;34(10): 4268-74.

[26] Barsoukov E, Macdonald JR. Impedance spectroscopy: theory, experiment and applications. 2nd ed. New Jersey: John Wiley \& Sons; 2005.
[27] Aroutiounian VM, Arakelyan VM, Shahnazaryan GE, Stepanyan GM, Turner JA, Khaselev O. Investigation of ceramic $\mathrm{Fe} 2 \mathrm{O} 3<\mathrm{Ta}>$ photoelectrodes for solar energy photoelectrochemical converters. International Journal of Hydrogen Energy 2002;27(1):33-8.

[28] Nozik AJ. Photoelectrochemistry: applications to solar energy conversion. Annual Review of Physical Chemistry 1978;29(1): 189-222.

[29] Aruchamy A, Aravamudan G, Subba Rao G. Semiconductor based photoelectrochemical cells for solar energy conversion-an overview. Bulletin of Materials Science 1982; 4(5):483-526. 